\title{
Control and PWM Modulation Scheme for Dead-Time Compensation of CVCF Inverters
}

\author{
Zhongwei Guo ${ }^{1}$, Fujio Kurokawa ${ }^{2}$ \\ ${ }^{1}$ Shindengen Electric Mfg. Co., Ltd., Japan \\ ${ }^{2}$ Department of Electrical and Electronic Engineering, Nagasaki University, Japan \\ E-mail: ${ }^{1} k a k u @$ shindengen.co.jp, ${ }^{2}$ fkurokaw@nagasaki-u.ac.jp
}

\begin{abstract}
The switching dead-time necessary in PWM inverters results in output distortions, and deteriorates the utilization of dc-link voltage. To solve these problems, the authors have developed an accurate dead-time effect mathematical model, and proposed a compensation scheme for grid-connected inverters. In this paper, a new voltage control and PWM modulation scheme is presented for the dead-time compensation of CVCF inverters. It consists of a PID voltage controller and a sliding mode controller (SMC). The PID controller operates in the linear areas; the SMC controller detects the dead-time nonlinear operations and operates for the dead-time compensation. In this control scheme, the PWM modulation gate drive is divided into three operation modes according to the SMC controller output. The unnecessary gate drive signals are removed and the counter side switch can be controlled up to truly $100 \%$ PWM duty ratio with a smooth transition between different modulation modes. The influence of switching dead-time can be eliminated almost completely.

The proposed control scheme is verified by simulation results. The improvement of harmonic distortion, the minimization of dclink voltage and the reduction of inductor ripple current are all confirmed by the simulation results. The comparison results between the conventional and the proposed control scheme are presented in this paper.
\end{abstract}

\section{INTRODUCTION}

$\mathrm{DC} / \mathrm{AC}$ inverters are widely used in the telecommunication and data communication systems. Besides the power quality, low cost, small size and high efficiency are the major issues in the power inverters. To address these issues, the industry prefers a higher switching frequency and smaller passive components such as capacitor and inductor.

The dead-time necessary in PWM inverters results in output distortions, and deteriorates the utilization of dc-link voltage. To acquire the desired power quality, a higher dc-link voltage is required, that results in large switching losses [1] and large ripple current. Due to the large inductor ripple current and the high operation voltage of dc-link capacitor, the inductor iron loss increases and a larger dc-link capacitor is required. That will result in large size and high cost. The minimization of dclink voltage will improve the conversion efficiency and contribute to a reduced size.

For high power quality solutions of power inverters, various control strategies have been investigated for dead-time compensation [2], [3]. Usually the compensation techniques are based on the current polarity. But in the case when a small inductor is used in the LC filter, because of the influence of switching ripple current, it may malfunction and worsen the power quality on the contrary.

To solve these problems, a new voltage control and PWM modulation scheme is proposed in this paper. The proposed controller consists of a sliding controller (SMC) and a PID voltage controller. The PID controller is active when the inverter operates in linear areas. When the dead-time nonlinear operations are detected, the SMC controller operates for the dead-time compensation. According to the SMC controller output, the unnecessary gate drive signals are removed and the counter side switch can be controlled up to $100 \%$ PWM duty ratio with a smooth transition between different dead-time effect modes. That will maximize the dc-link voltage utilization and improve the harmonic distortion. Since the unnecessary gate drive signals are removed, the switching loss caused by the turn-off tail current can be reduced.

\section{Circuit AND CONTROl CONFiguration}

\section{A. Circuit Configurations}

The inverter circuit is shown in Fig. 1 and the parameters shown in Table 1 are used in the system. The inverter system consists of a dc/dc converter, a dc-link capacitor, a voltage source inverter, and an LC filter circuit. In this Figure, $\mathrm{V}_{\mathrm{dc}}$ is the dc-link voltage, $\mathrm{L}_{\mathrm{f}}$ and $\mathrm{C}_{\mathrm{f}}$ are the inductor and capacitor of LC filter, and $\mathrm{Z}_{\mathrm{L}}$ represents the load connected to the inverter output.

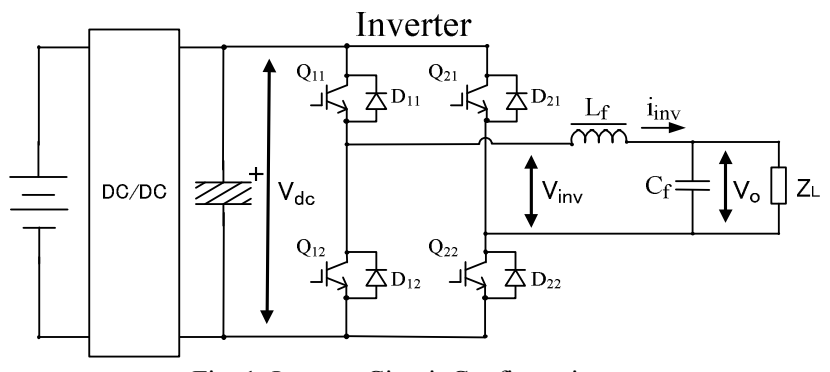

Fig. 1. Inverter Circuit Configuration.

TABLE I. SYSTEM PARAMETERS

\begin{tabular}{|l|l|}
\hline Filter inductor & $1 \mathrm{mH}$ \\
\hline Filter capacitor & $20 \mathrm{uF}$ \\
\hline Carrier frequency & $20 \mathrm{kHz}$ \\
\hline Dead-time & $3 \mu \mathrm{s}$ \\
\hline Rated output power & $1 \mathrm{kVA}$ \\
\hline
\end{tabular}




\section{B. Conventional PID control}

Figure 2 shows the inverter control configuration and Fig. 3 shows the PID control block diagram. The PWM duty ratio is obtained by Eq. (1). To prevent the short circuit of dc-link voltage, dead-time is inserted between the commutations.

$$
D=\frac{\left(u+V_{o}^{*}\right) / V_{d c}+1}{2}
$$

where $u$ is the output of PID controller, $V_{o}^{*}$ is the inverter voltage reference, and $V_{\mathrm{dc}}$ is the dc-link voltage.

Considering an ideal switch case, neglecting the non-ideal characteristics of the circuit components, the closed-loop transfer function of the inverter can be expressed as Eq. (2).

$$
\frac{V_{o}}{V_{o}^{*}}=\frac{K_{d} s^{2}+\left(1+k_{p}\right) s+k_{i}}{L_{f} C_{f} s^{3}+K_{d} s^{2}+\left(1+k_{p}\right) s+k_{i}}
$$

where $\mathrm{s}$ is the Laplace operator, $V_{o}^{*}$ is the reference of inverter voltage, $\mathrm{K}_{\mathrm{p}}$ is proportional gain, $\mathrm{K}_{\mathrm{i}}$ is the integral gain, and $\mathrm{K}_{\mathrm{d}}$ is the derivative gain of the PID controller.

In the time domain, the derivative of inverter voltage can be expressed as Eq. (3).

$$
\frac{d e_{v}}{d t}=\frac{d\left(V_{o}^{*}-V_{o}\right)}{d t}=\frac{i_{c}^{*}}{C_{f}}-\frac{i_{c}}{C_{f}}
$$

where $i_{c}^{*}$ is the reference of capacitor current which can be obtained by Eq. (4), $i_{c}$ is the capacitor current which can be

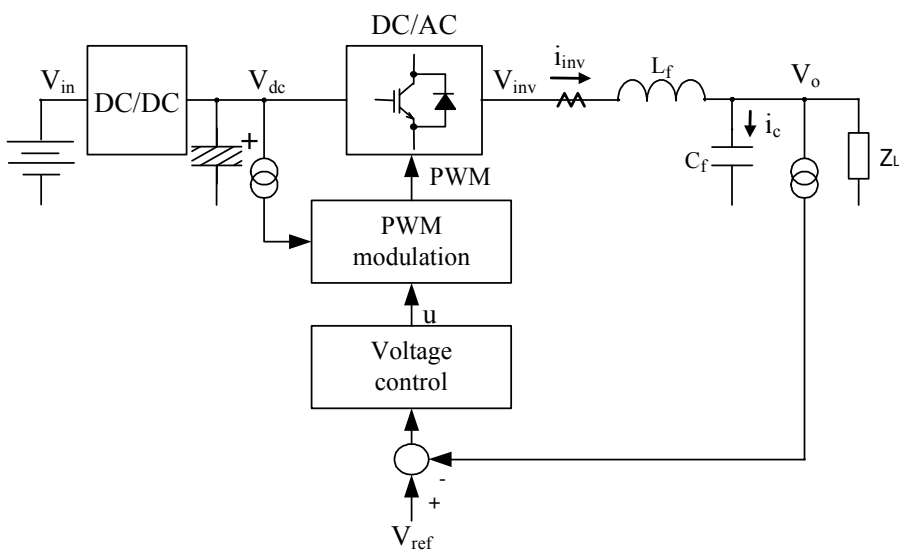

Fig. 2.Inverter control configuration.

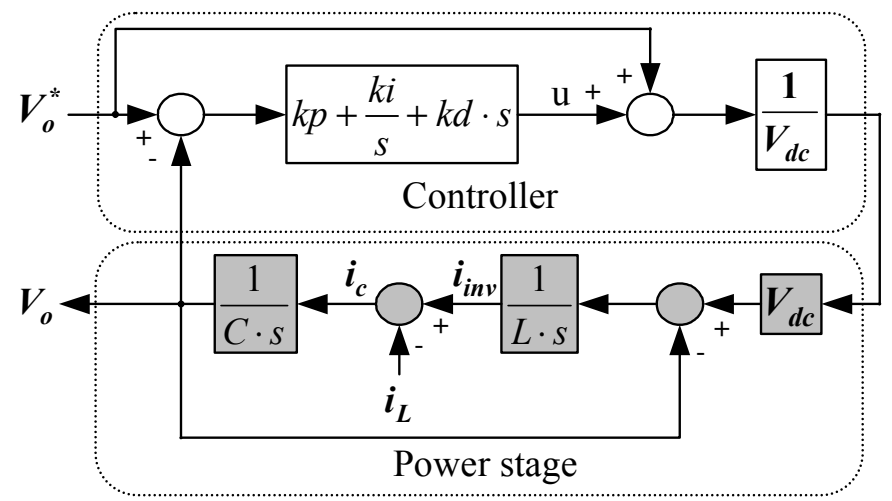

Fig. 3.Inverter voltage control block diagram (Conventional). measured directly, or calculated by the difference of inductor current and load current measurement result.

$$
i_{c}^{*}=C_{f} \cdot \frac{d V_{o}^{*}}{d t}=\omega \cdot C_{f} \cdot \cos (\omega t)
$$

In this paper, to alleviate the influence of measurement noise, the proportional control of capacitor current is adopted instead of the derivative calculation of output voltage.

With appropriate control parameters and a relative small dead-time, low distortion voltage output can be obtained at the inverter output. However, with a high switching frequency and when a relative large dead-time is applied, the dead-time effects give large influence on the inverter operations.

Figure 4 shows the output voltage simulation result at the condition of $\mathrm{V}_{\mathrm{dc}}=180 \mathrm{~V}$. Due to the dead-time effect, on the positive side and the negative side near the zero crossing point, significant voltage distortions can be observed.

Figure 5 shows the simulation waveforms at the condition of $\mathrm{V}_{\mathrm{dc}}=150 \mathrm{~V}$ and the modulation signal is limited to less than $100 \%$ duty ratio. Together with the zero crossing distortion, the required voltage output can't be obtained.

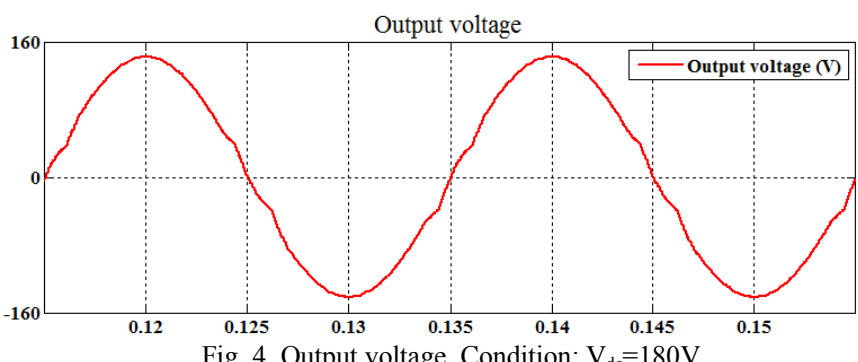

Fig. 4. Output voltage, Condition: $\mathrm{V}_{\mathrm{dc}}=180 \mathrm{~V}$

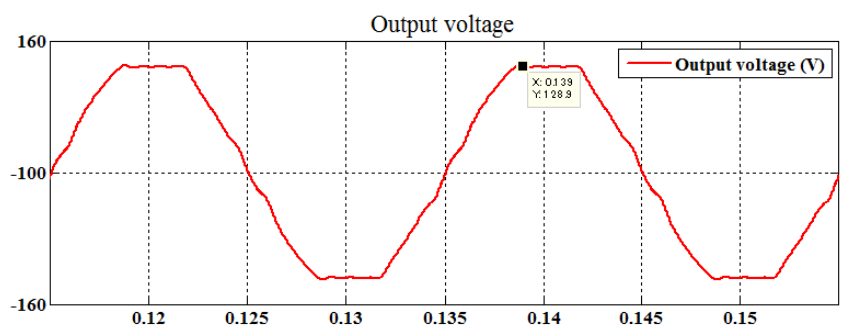

Fig. 5. Output voltage, Condition: $\mathrm{V}_{\mathrm{dc}}=150 \mathrm{~V}$, modulation signal is limited to $0.4 \%-99.6 \%$ duty ratio.
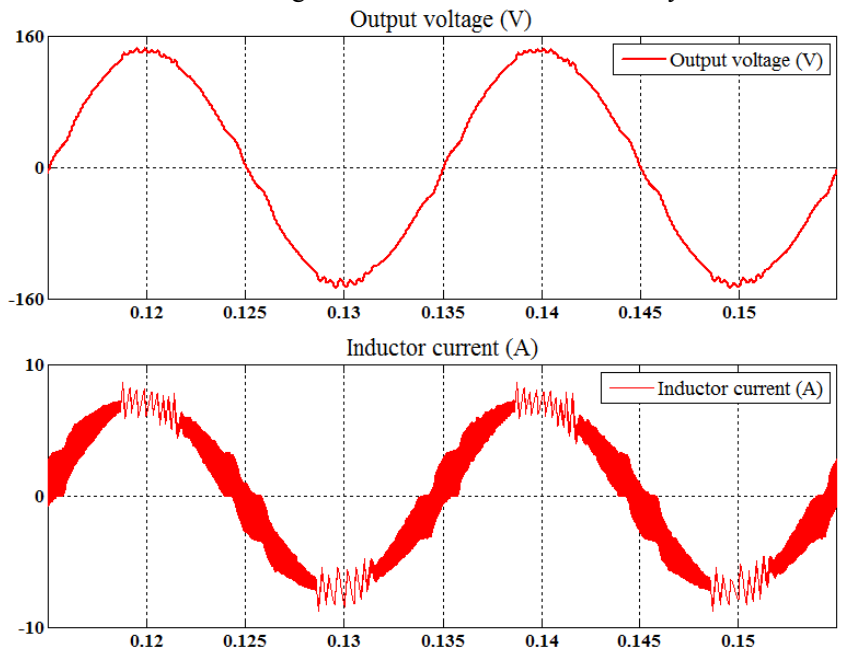

Fig. 6. Output voltage, Condition: $\mathrm{V}_{\mathrm{dc}}=150 \mathrm{~V}$, without limitation of modulation index 
As shown in Fig. 6, without the limitation of modulation signal, although the maximum voltage amplitude can be achieved, low frequency ripple voltage and ripple current occurs, that may results in large audible noise.

\section{The Proposed CONTROL SCHEME}

\section{A. Dead-time effect}

For grid-connected inverter, in reference [4], by analyzing the PWM modulation signals and the influence of switching ripple current, an accurate dead-time error mathematical model is developed. The model is shown in Fig. 7, in this model, the dead-time effects are divided into five modes according to the inductor current and the switching ripple current. In mode 1 and 5, a positive or a negative error voltage appears. In mode 2 and 4, instead of the inductance characteristics, resistive characteristics can be observed between the reference voltage $\left(\mathrm{V}_{\text {ref }}\right)$ and the inductor current. In mode 3 , if the turn off delays of the positive switch and the negative switch are the same, ideal switch characteristics can be obtained.

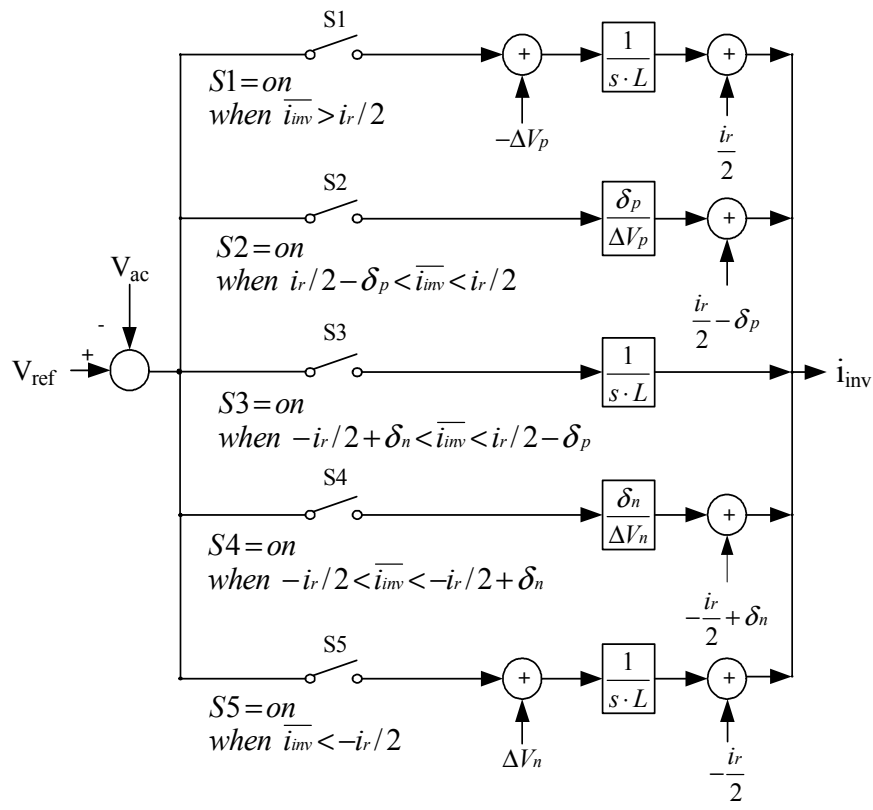

Fig. 7. Dead-time effect mathematical model.
This dead-time effect mathematical model can also be applied for CVCF inverters, including the non unity power factor load and the nonlinear load condition.

For the inverter circuit shown in Fig. 1, neglecting the turn on and turn off delay of the power switch. The dead-time error voltages of $\Delta V_{p}$ and $\Delta V_{n}$ can be expressed as Eq. (5).

$$
\Delta V=\frac{2 \cdot T_{d}}{T_{c}} \cdot V_{d c}
$$

Calculated by the parameters shown in Table I, the deadtime error voltage is $12 \%$ of the dc-link voltage; only $88 \%$ voltage transfer ratio can be obtained. To output the same voltage, the dc-link voltage should be $13.6 \%$ higher than the ideal switch condition.

\section{B. The proposed Control Scheme}

For the objective of attaining good performance under parameter and load variations, sliding mode control approaches were investigated for the power converter control [5-7]. In this paper, together with a linear PID controller, according to the dead-time model shown in Fig. 7, a sliding mode controller is proposed for the dead-time compensation of CVCF inverters.

Figure 8 shows the proposed controller configuration. The control scheme consists of a PID controller and a SMC controller. The PID controller operates in the linear operation areas; it is designed with the previous introduced method. The SMC controller detects the dead-time nonlinear operations and output the dead-time error voltage for the dead-time compensation. The details are presented hereafter.

Considering the nonlinear operations as model error of the linear model, the relation between the controller output and the inductor current can be expressed as Eq. (6).

$$
V_{r e f}=V_{o}+L_{f} \cdot \frac{d i_{i n v}}{d t}+\varepsilon
$$

where $\mathrm{V}_{\text {ref }}$ is the modulation reference voltage, $\mathrm{V}_{\mathrm{o}}$ is the output voltage, $\mathrm{i}_{\text {inv }}$ is the inductor current, $\mathrm{L}_{\mathrm{f}}$ is the inductor inductance of LC filter, $\varepsilon$ represents the model error caused by the nonlinear characteristics such as dead-time effect. With a PID controller and the feed forward of instant voltage reference, $\mathrm{V}_{\text {ref }}$ can be expressed as Eq. (7).

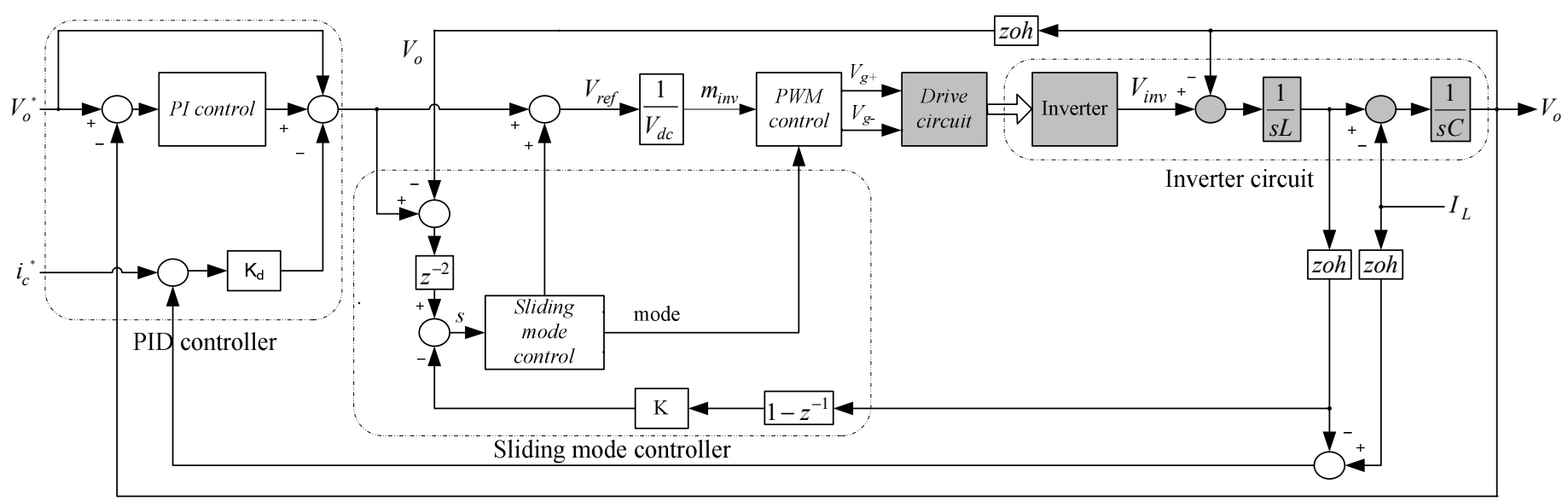

Fig. 8. The proposed voltage control scheme. 


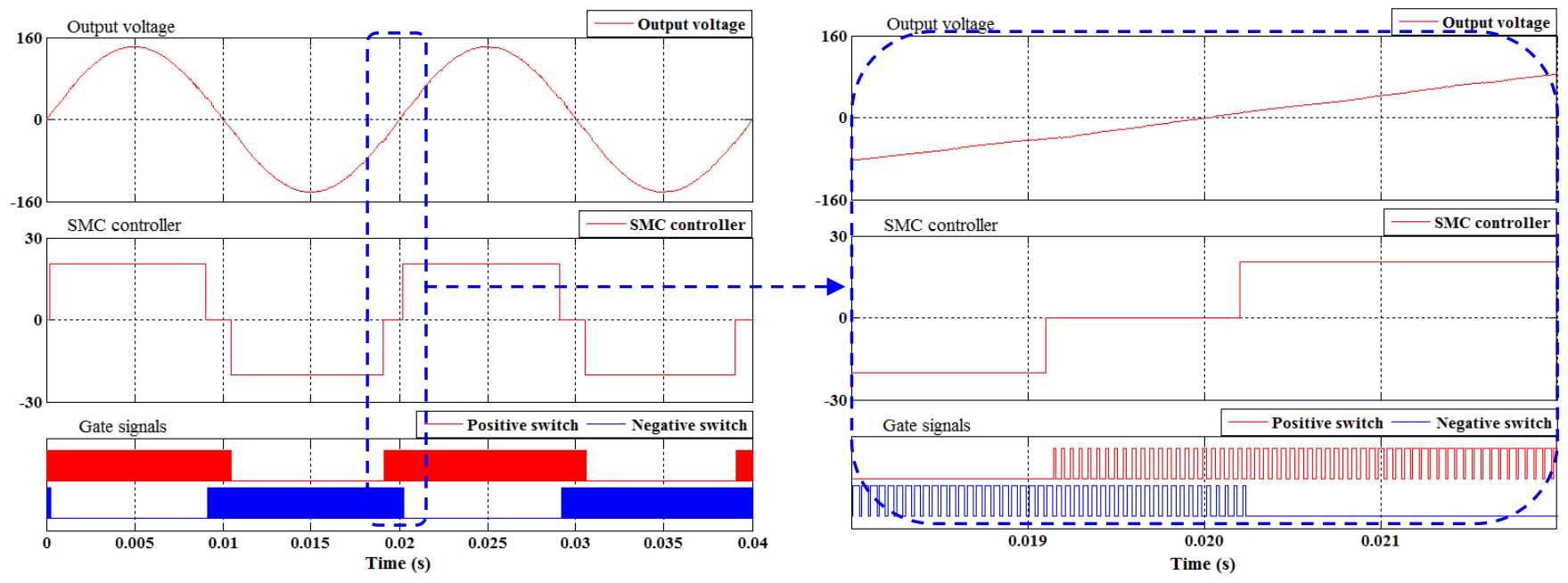

Fig. 9. PWM modulation gate control.

$$
V_{\text {ref }}=K_{p} \cdot e+K_{i} \cdot \int e+K_{d} \cdot \dot{e}+V_{o}^{*}
$$

The derivative of inductor current can be approximated as Eq. (8).

$$
d i_{i n v} / d t=\left(i_{i n v}(n)-i_{i n v}(n-1)\right) / T_{c}
$$

where $T_{c}$ is the switching period. Because the dead-time error voltage is the major part of the model error. From Eqs. (6), (7) and (8), a sliding mode function shown in Eq. (9) can be obtained.

$$
S=K_{p} \cdot e+K_{i} \cdot \int e+K_{d} \cdot \dot{e}+V_{o}^{*}-V_{o}-K \cdot\left(i_{i n v}(n)-i_{i n v}(n-1)\right)
$$

With this function, the SMC controller outputs the deadtime compensation signal according to the control law defined in Eq. (10).

$$
\mathrm{u}_{\mathrm{n}}= \begin{cases}\Delta \mathrm{V}_{\mathrm{p}} & \text { when }(\mathrm{S}>\varepsilon) \text { and }\left(\mathrm{u}_{\mathrm{n}-1} \geq 0\right) \\ 0 & \text { when }\left((\mathrm{S}>\varepsilon) \text { and }\left(\mathrm{u}_{\mathrm{n}-1}<0\right)\right) \text { or } \\ -\Delta \mathrm{V}_{\mathrm{n}} & \left((\mathrm{S}<-\varepsilon) \text { and }\left(\mathrm{u}_{\mathrm{n}-1}>0\right)\right) \\ \text { when }(\mathrm{S}<-\varepsilon) \text { and }\left(\mathrm{u}_{\mathrm{n}-1} \leq 0\right)\end{cases}
$$

where $\Delta V_{p}$ and $\Delta V_{n}$ represents the positive and the negative dead-time error voltage that can be calculated by the deadtime value and adjusted by a parameter auto-tuning method. The hysteresis of $\mathcal{E}$ is applied to avoid the control chattering and eliminate the influence by measurement noise.

\section{Switch Gate Drive Control}

Figure 9 shows the PWM modulation gate control operation. The gate signals of $Q_{11}$ and $Q_{12}$ are shown in this figure. When the SMC controller outputs a positive value, the gate signal of negative switch $\mathrm{Q}_{12}$ is removed and the positive switch $\mathrm{Q}_{11}$ is controlled by a PWM signal without inserting the dead-time. If the SMC controller outputs a negative value, the positive switch gate signal is removed. Otherwise, both of the switch gate signals are controlled on/off with a dead-time inserted between the commutations. Because the unnecessary charge and discharge of the IGBT internal gate is eliminated, the tail current loss can be reduced.

\section{Simulation VerificAtion}

The proposed voltage control and PWM modulation control scheme are verified in MATLAB/Simulink and SimPowerSystems simulation environment. The control algorithm is implemented by MATLAB language code.

The inverter circuit shown in Fig. 1 and the parameters shown in Table I are used for the simulation. The comparisons between the PID controller without the dead-time compensation and the proposed controller are presented in this section.

Figure 10 shows the waveforms of the proposed control

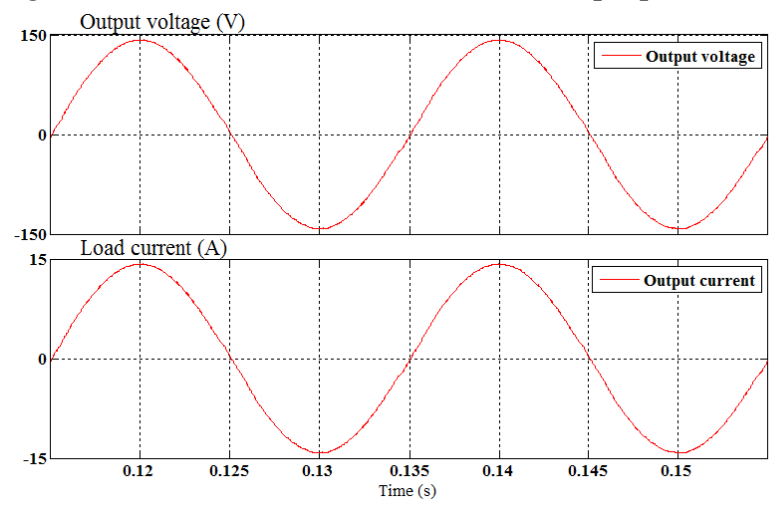

Fig. 10. Simulation waveforms with rated resistive load. $\mathrm{V}_{\mathrm{dc}}=180 \mathrm{~V}$.

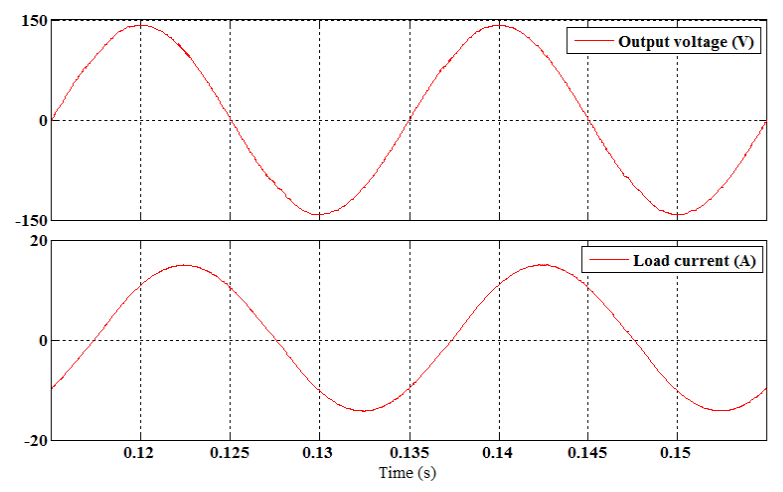

Fig. 11. Simulation waveforms with rated 0.7 lagging power factor load, $\mathrm{V}_{\mathrm{dc}}=180 \mathrm{~V}$. 
with a rated resistive load. Compared with the waveform shown in Fig. 4, the harmonic distortion is greatly reduced.

Figure 11 shows the waveforms of the proposed control with a 0.7 lagging power factor load, low distortion output is obtained in the none unity power factor load condition.

Figure 12 shows the waveforms with a rectifier load. The crest factor is about 2.97 , with a peak current of $18.6 \mathrm{~A}$. The effectiveness is confirmed in the nonlinear load condition.

Figure 13 shows the waveforms with a decreased dc-link voltage, compared with the voltage waveform shown in Fig. 5, a low distortion and the desired voltage can be obtained. With the proposed control method, the dc-link voltage can be decreased from $170 \mathrm{~V}$ to $150 \mathrm{~V}$. $20 \mathrm{~V}$ reduction of dc-link voltage can be achieved.

Figure 14 shows the voltage THD (total harmonic distortion) comparison with resistive load. In all of the load range, the total harmonic distortion decreases to about 1/3-1/2 of the conventional.

Figure 15 shows the voltage THD (total harmonic distortion) comparison with rectifier load. The total harmonic distortion decreases to about $1 / 3-2 / 3$ of the conventional.

Figure 16 shows the transient response of the inverter with the load changing from no load to the rated resistive load. The inverter provides fast response to the load change transient.

Figure 17 shows the inductor ripple current decrease. The decreases of dc-link voltage from $170 \mathrm{~V}$ to $150 \mathrm{~V}$ will contribute to a $19 \%$ reduction of inductor switching ripple current. The iron losses can be reduced by a corresponding level.

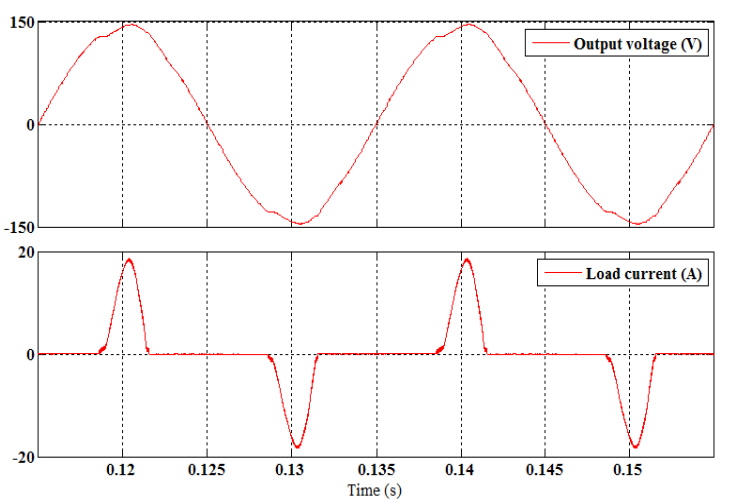

Fig. 12. Simulation waveforms with rectifier load, $\mathrm{V}_{\mathrm{dc}}=180 \mathrm{~V}$

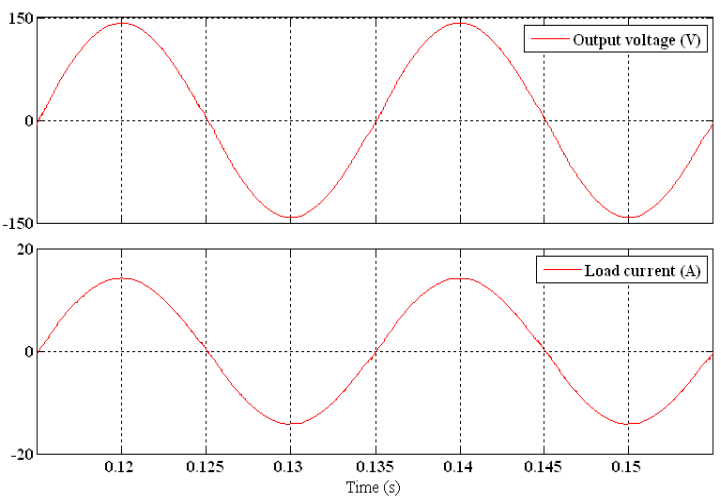

Fig. 13. Simulation waveforms with resistive load, $\mathrm{V}_{\mathrm{dc}}=145 \mathrm{~V}$.

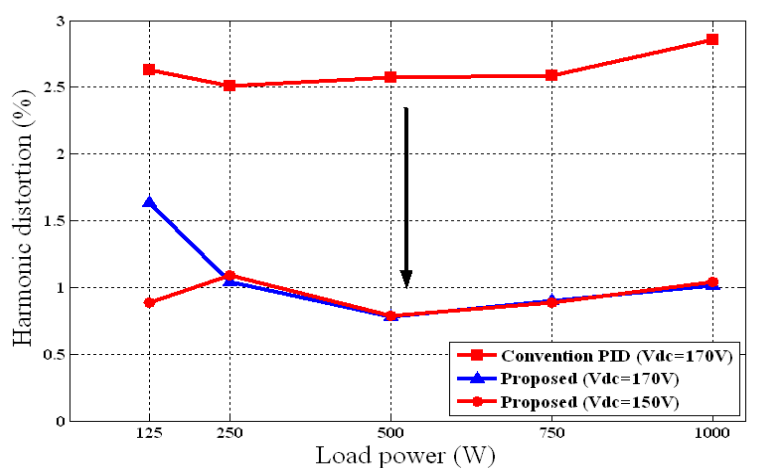

Fig. 14. Total harmonic distortion comparison with resistive load.

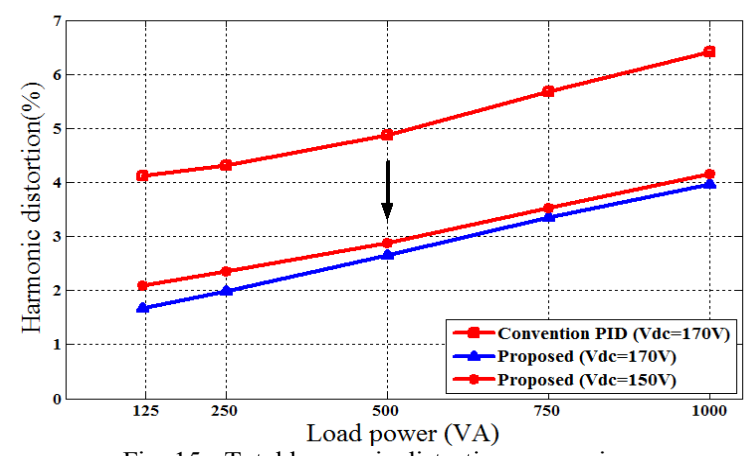

Fig. 15. Total harmonic distortion comparison with rectifier load.

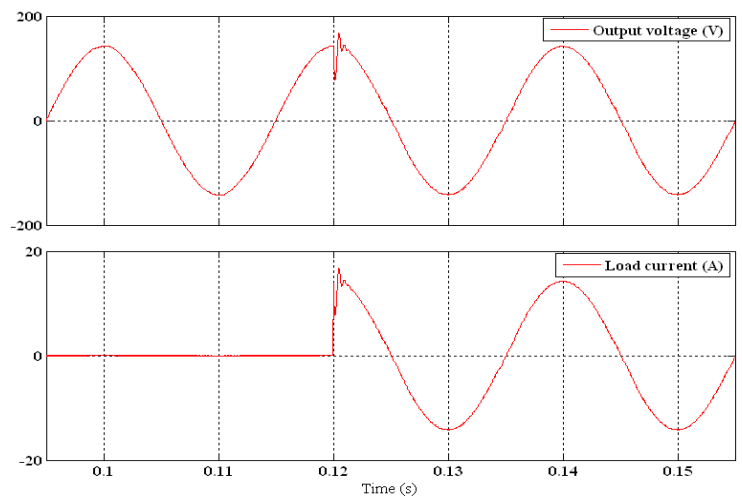

Fig. 16. Load change from no load to the rated load.

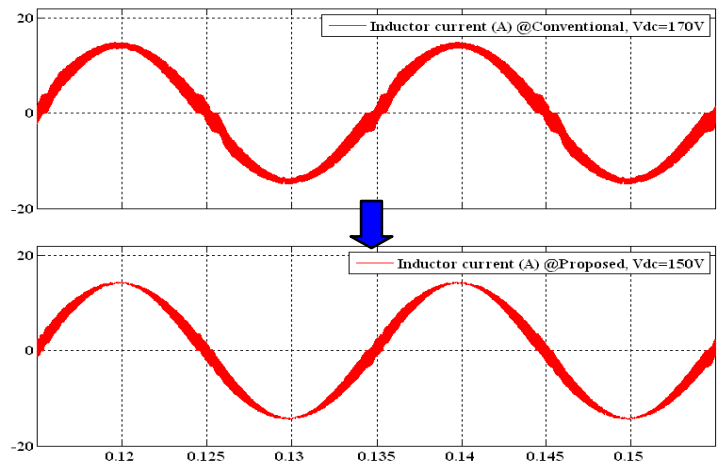

Fig. 17. Inductor current of AC filter. (Switching ripple component: 0.858Arms->0.696Arms). 


\section{CONCLUSION}

This paper presented a new voltage control and PWM modulation gate control scheme for dead-time compensation of CVCF inverters. The proposed control scheme consists of a SMC controller and a PID voltage controller. The SMC controller detects the dead-time nonlinear operations and operates for the dead-time compensation; the PID controller operates in the linear areas. In this control scheme, the PWM modulation gate drive is divided into three operation modes according to the SMC controller output. The unnecessary gate drive signals are removed and the counter side switches are controlled up to truly $100 \%$ PWM duty ratio with a smooth transition between different modulation modes. With this control scheme, the influence of dead-time can be eliminated, and the harmonic distortion can be greatly reduced. The minimization of dc-link voltage will contribute to a reduced switching loss and a small inductor ripple current. Compared with the conventional PID control, the following improvements are confirmed by simulation results.

(1) The harmonic distortion is decreased to about 1/3-1/2 of the conventional, the effectiveness are also confirmed in the non unity power factor load and nonlinear load condition.

(2) In the studied system, the dc-link voltage can be reduced by about $14 \%$. The inductor ripple current is reduced by about $19 \%$. With a lower dc-link voltage, the dc-link capacitor size can be reduced.

(3) With a low dc-link voltage, and the new gate drive control strategy, the efficiency improvements can be expected.

The proposed control scheme will be experimented in a DSP controller based inverter system, and only some program codes are needed.

\section{REFERENCES}

[1] M.H. Bierhoff and F.W. Fuchs, "Semiconductor Losses in Voltage Source and Current Source IGBT Converters Based on Analytical Derivation," IEEE PESC Record, pp.2836-2842, 2004.

[2] J. Kang, G. Xu, J. Xu and C. Zhou, "Study of Compensation Method on Dead-time Effects for VSI Fed Drive Systems", in Proc. IEEE PESC, pp.548-552(2007).

[3] A.R.Munoz, T.A. Lipo. On-Line Dead Time Compensation Technique for Open-Loop PWM-VSI Drives. IEEE Trans. on Power. Elec. Vol. 14. No. 4. pp. 683-689(1999).

[4] Z. Guo, F. Kurokawa, and F. Furuya, "A study of inverter de Link voltage minimization scheme with an adaptive sliding mode controller", Technical report of IEICE. EE2008-47, pp.17-22 (2008) (in Japanese).

[5] A.G. Perry, G. Feng, Y-F. Liu, P.C. Sen,"A New Sliding Mode Like Control Method for Buck Converter," IEEE PESC Record, pp.36883693, 2004.

[6] Siew-Chong Tan, Y.M. Lai, Chi K. Tse, and Martin K.H. Cheung, "An adaptive sliding mode controller for buck converter in continuous conduction mode," in Proc. IEEE APEC, pp. 1395-1400, 2004.

[7] F. Xu, T. Zhang, H. Ma and Y. Zhang, "The Sliding Mode Controller Based on Reference Triangular Wave for Buck Inverter, " IEEE PESC Record, pp.516-519, 2007. 